\title{
Syntactic Sources of Adjectives in Mandarin Chinese
}

Feng-hsi Liu

University of Arizona

\begin{abstract}
Cinque $(2010,2014)$ shows that in English and Italian, adjectives have two syntactic sources, each with different interpretive properties; one source corresponding to predicative adjectives; the other to non-predicative adjectives. This study examines adjectives in Mandarin Chinese with the goal of finding out whether Chinese displays the same pattern. The data shows that Chinese behaves similarly to English and Italian; adjectives that are derived from relative clauses are semantically different from those that directly modify nouns. In addition, Chinese displays the correspondence that predicative adjectives are derived from reduced $\mathrm{RC}$, while nonpredicative adjectives participate in direct modification. However, this parallelism is only possible if we modify the line drawn between "predicative" and "nonpredicative" assumed by Chinese grammarians.
\end{abstract}

\section{Keywords}

adjectives, nonpredicative, direct modification, relative clauses

Studies in Chinese Linguistics, Volume 37, Number 1, 2016, 38-55 DOI: 10.1515/scl-2016-0002 (C)2016 by T.T. Ng Chinese Language Research Centre, Institute of Chinese Studies, The Chinese University of Hong Kong 


\section{Introduction}

Cinque (2014), largely based on Cinque (2010), argues that adnominal adjectives come from two syntactic sources each with a different set of interpretative properties, given in (1) (Cinque 2014, p. 2):

(1) Reduced RC source

restrictive reading

intersective reading

implicit $\mathrm{RC}$ reading with $\mathrm{ACD}$

of "possible"

relative (to a comparison class)

reading

comparative reading

(of superlatives)

epistemic reading of "unknown"

discourse anaphoric reading

of "different"

specific or nonspecific reading stage-level or individual-level reading

literal reading

\section{Direct modification source}

nonrestrictive reading nonintersective reading modal reading of "possible"

absolute reading

absolute reading (of superlatives)

evaluative reading of "unknown"

NP-dependent reading of "different"

specific reading

individual-level reading

literal or idiomatic reading

Evidence is presented from English and Italian. In English, postnominal adjectives are derived from relative clauses only, while in Italian, prenominal adjectives indicate direct modification only. The two languages, therefore, provide a window into interpretative properties associated with each of the two syntactic strategies. Cinque shows that the classification in (1) has implications for semantic classification of adjectives concerning intersective, subsective, and nonsubsective adjectives. Following Partee (2007, 2009, 2010), he concludes that the distinction in (1) corresponds to the traditional distinction of predicative vs. nonpredicative adjectives.

When we look at Mandarin Chinese (henceforth Chinese), the following questions naturally arise: Do adjectives in Chinese also have two syntactic sources as outlined by Cinque? Do they also show meaning differences along the line of (1)? If so, do these differences correspond to the predicative versus non-predicative distinction, as suggested for English? To date, there have been two views concerning the syntactic sources of adjectives in Chinese. Sproat and Shih (1991) propose two syntactic sources for Chinese adjectives. However, their proposal runs into difficulty when applied to the entire groups of adjectives (Section 2). On the other hand, Paul $(2005,2010)$ focuses on what cannot be the syntactic source for some of the adjectives, but she does not address the issue of what the syntactic sources of adjectives are. In this note, I consider this issue by looking at different sub-types of adjectives. I suggest that Sproat and Shih (1991)'s analysis is largely on the right track; their view is supported if it is applied not to all of the adjectives, but to 
predicative adjectives only. I provide additional support for this view by bringing in evidence from interpretative properties discussed by Cinque, subsumed under (1). I will show that Chinese is similar to English with respect to the association between syntactic sources and types of adjectives.

\section{Two distinctions}

Any discussion of Chinese adjectives needs to take two distinctions into account. First is the distinction between predicative and nonpredicative adjectives, which was discussed during the 1950s and 1960s (e.g., Zhu 1980 [1956], 1982, Lü and Rao $1981^{1}$ ). In this tradition, predicative adjectives are ones that have the potential to serve as predicates, while nonpredicative adjectives are ones that cannot function as predicates. Nonpredicative adjectives are illustrated in (1) and (2):
a. zhuyao (de) daolu
major DE road
"major road"
b. gongtong (de) xingqu
shared DE interest
"shared interest"
$\begin{array}{lll}\text { c. daxing (de) yinyuehui } & \end{array}$
large-scale DE concert
"large-scale concert"

(2) a. *Zhe tiao daolu xiangdang zhuyao.

this CL road quite major

?"This road is quite major."

b. *Women liangge de xingqu shifen gongtong. we two-CL DE interest very shared

"The two of us have shared interest."

c. *Mingtian de yinyuehui jiang feichang daxing tomorrow DE concert will very big-scale

?"The concert tomorrow will be rather big-scale."

(2) shows that these adjectives cannot function as predicates. Predicative adjectives are illustrated in (3):

(3) a. Wo yujian yige keai de xiaohai

I met one-CL cute DE child

"I met a cute child."

b. Zhege xiaohai hen keai

this-CL child very cute

"This child is very cute."

1 According to the authors, the article was first written in 1965 , but because of the Cultural Revolution, it did not appear until 1981. 
(4) a. Laoban zuo-le yige zhongyao de jueding boss make-PERF one-CL important DE decision "The boss made an important decision."

b. Zhege jueding hen zhongyao this-CL decision very important "This decision is very important."

(3b) and (4b) show that keai "cute" and zhongyao "important" can be used as a predicate. Although the predicative versus nonpredicative distinction was not discussed in the context of syntactic sources during 1950s and 1960s, it is not difficult to see that it has syntactic implications. Cases such as (3) and (4) support the view that the adjectives in (3a) and (4a) are derived from relative clauses (Sproat and Shih 1988, 1991), whereas sentences in (2) suggest that the adjectives in (1) cannot come from relative clauses, as the would-be source sentences are unacceptable.

Thus the predicative versus nonpredicative distinction has an immediate consequence on the syntactic source of an adjective. If an adjective is nonpredicative, it cannot come from a relative clause. This point has been made by Paul (2005, 2010) and Aoun and $\mathrm{Li}$ (2003). But what happens when an adjective is predicative? Is it always derived from a relative clause? This is an issue I will return to below. In fact, in answering this question, I will make the suggestion that the line drawn between predicative and nonpredicative, as assumed by Chinese grammarians, needs to be modified. But before that, I will continue to use the terms as presented in Lü and Rao (1981).

The second distinction concerns the presence or absence of $d e$, which gives rise to two modification structures: Adj de $\mathrm{N}$ and Adj N. This distinction has also been widely discussed (Fan 1958, Zhu 1980 [1956], Duanmu 1998, Sproat and Shih 1988, 1991, Paul 2005, 2010, among others). It plays a major role in the syntax and semantics of Chinese adjectives. For now, I note two characteristics of the distinction; we will see other features later. First, while Adj $d e \mathrm{~N}$ is productive, Adj $\mathrm{N}$ has gaps. (5) and (6) gives some examples:

(5) a. huaji de dianying huaji dianying (Zhu 1980[1956]: 10) funny DE movie funny movie "funny movie"

b. huaji de ren *huaji ren funny DE person funny person "funny person"

(6) a. zhongyao de renwu zhongyao renwu important DE person important person "important person"

b. zhongyao de guanjia *zhongyao guanjia important DE housekeeper important housekeeper "important housekeeper" 
The second feature, related to the first, is that sometimes the same adjective may occur in either form. It is demonstrated in (1) for nonpredicative adjectives and in (5a) and (6a) for predicative adjectives.

In previous studies, there have been attempts relating the form of modification (with or without de) to syntactic properties. Such attempts go in two directions. First, the form of a modification structure may be indicative of the syntactic status of the modifier-head expression: while Adj $d e \mathrm{~N}$ is a phrase, Adj $\mathrm{N}$ is a word. The issue concerning the syntactic status of Adj $\mathrm{N}$ has long been noted, but to date, no consensus has been reached. Lü (1979) lists three possible ways to handle Adj $\mathrm{N}$ and Adj de $\mathrm{N}$ syntactically: (a) both Adj $\mathrm{N}$ and Adj de $\mathrm{N}$ are phrases; Adj $\mathrm{N}$ is a basic phrase, while Adj de $\mathrm{N}$ is an expanded phrase; (b) Adj $\mathrm{N}$ is a word, while Adj de $\mathrm{N}$ is a phrase; and (c) Adj $\mathrm{N}$ is a phrasal word ("duanyu ci"). Zhu (1982: 168-170) treats both Adj N and Adj de N as modifier-head phrasal structures ("pianzheng jiegou"), and their difference lies in how the modifier and head are put together: the former has an agglutinating structure ("nianhe shi") and the latter has a combinatory structure ("zuhe shi"). The compound analysis for Adj N is proposed by Sproat and Shih (1988) and Duanmu (1998). Sproat and Shih (1991), however, reverse their earlier position and assume that Adj $\mathrm{N}$ can be a phrase. They note (p. 592) that Adj N is quite productive. Paul (2005) offers strong arguments against the compound analysis. I am in agreement with the latter view: Adj $\mathrm{N}$ can be a phrase, although there are also compounds with the same internal structure. The burden of proof is actually on supporters of the compound analysis, because on this view, it is assumed that adjectives in Chinese are unable to directly modify a noun. But this assumption is not justified. In other parts of the grammar, direct modification is certainly available, for example, adverbs modifying a verb or an adjective, for example, mianqiang tongyi "reluctantly agree," feichang kuai "very fast," and verbs modifying a noun, for example, zhunbei shijian "preparation time."

The second way that relates the $\operatorname{Adj} \mathrm{N}$ versus Adj $d e \mathrm{~N}$ distinction to syntax is that the form of modification is indicative of the syntactic source of the adjective: Adj de $\mathrm{N}$ comes from relative clauses, while Adj $\mathrm{N}$ does not. This is the position that Sproat and Shih $(1988,1991)$ take. However, Paul $(2005,2010)$ argues against the relative clause analysis for Adj $d e \mathrm{~N}$ in general. The evidence that Paul cites comes from nonpredicative adjectives. As we saw above, non-predicative adjectives, which cannot come from relative clauses, also occur in the form of Adj de N. Thus it is not the case that Adj de $\mathrm{N}$ is always derived from relative clauses. Following Cinque, I will refer to the type of modification whose source does not come from a reduced relative clause but from the combination of an adjective and a noun as direct modification. Sproat and Shih (1991) also use this term, although they apply it to $d e$-less modification only. It should be clear, on the basis of nonpredicative adjectives, that direct modification also applies to some Adj de $\mathrm{N}$ phrases. 
(7) is what we have so far:

(7) Adjectives in Chinese

Adjectives

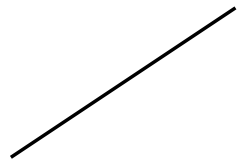

Nonpredicative

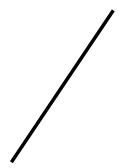

Without de<smiles>CI</smiles>

Direct mod
With de

$$
\mid
$$

Direct mod

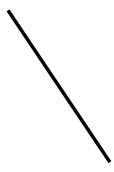

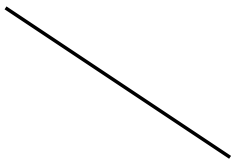

Predicative

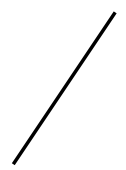

Without de

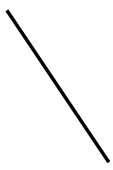

With de

$$
\mid
$$

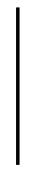

(7) immediately raises the following question: what are the syntactic source for predicative adjectives? I suggest that these adjectives have two sources, and it depends on whether they occur in Adj $\mathrm{N}$ or Adj de $\mathrm{N}$ : with-de adjectives come from relative clauses, while de-less adjectives participate in direct modification. This is essentially what Sproat and Shih $(1988,1991)$ propose, although, as noted earlier, their analysis runs into problems with nonpredicative adjectives. If we only look at predicative adjectives, however, the data supports two syntactic sources. The major evidence comes from differences in interpretation. In particular, the semantic differences of predicative adjectives between $\operatorname{Adj} \mathrm{N}$ and Adj de $\mathrm{N}$ follow Cinque's classification in (1). These differences are presented in the next section.

\section{Syntactic sources}

\subsection{Two syntactic sources for predicative adjectives}

In each of the following six cases, a de-less adjective has the reading given under "direct modification source" in (1), while the same adjective with de has the reading under "reduced RC source." 


\section{A. Restrictive versus nonrestrictive}

An adjective such as piaoliang "pretty" has a nonrestrictive meaning in an Adj $\mathrm{N}$ phrase, whereas in an Adj de $\mathrm{N}$ phrase, it has a restrictive meaning (the relevant parts are underlined):

(8) a. 最好我們挑選首長的漂亮公主, 如此神靈才可能真實確信我們對他的 虔誠乞求的心

Zuihao women tiaoxuan shouzhang de piaoliang gongzhu, ruci shenling cai had-better we pick chief DE pretty princess this-way god only keneng zhenshi quexin women dui ta de qiancheng qiqiu de xin possible genuinely believe we to him DE devout beg DE heart

"It would be better if we pick the chief's princess(es), who is/are pretty; only then would it be possible for the god to genuinely believe our devotion to him."

b. 最好我們挑選首長漂亮的公主, 如此神靈才可能真實確信我們對他的 虔誠乞求的心

Zuihao women tiaoxuan shouzhang piaoliang de gongzhu, ruci shenling cai had-better we pick chief pretty DE princess this-way god only keneng zhenshi quexin women dui ta de qiancheng qiqiu de xin possible genuinely believe we to him DE devout beg DE heart

"It would be better if we pick the chief's princess(es) who is/are pretty; only then would it be possible for the god to genuinely believe our devotion to him."

(8a) means that the daughters of the chief are pretty, while (8b) implies that not all of the chief's daughters are pretty.

\section{B. Intersective versus nonintersective}

An adjective such as meili "beautiful" has a nonintersective meaning in an Adj N phrase. In contrast, in an Adj de $\mathrm{N}$ phrase, it has an intersective meaning.

(9) a. 這位美麗舞者給人留下了深刻的印象

Zhewei meili wuzhe gei ren iuxia-le shenke de yinxiang this-CL beautiful dancer to people leave-PERF deep DE impression "The dancer, who dances beautifully, made a deep impression on people."

b. 這位美麗的舞者給人留下了深刻的印象

Zhewei meili de wuzhe gei ren iuxia-le shenke de yinxiang this-CL beautiful DE dancer to people leave-PERF deep DE impression "The dancer, who is beautiful, made a deep impression on people."

In (9a) the dancer is a wonderful dancer but as a person he/she is not necessarily good looking; (9b), on the other hand, gives the reading where the dancer is good looking. 
C. Absolute versus relative reading (in a comparison class)

An adjective such as kuankuo "wide" in an Adj $\mathrm{N}$ phrase has the absolute reading; in contrast, in an Adj de $\mathrm{N}$ phrase, kuankuo has the relative reading.

(10) a. 那一段又一段的寬闊海灘令人著迷。

Na yiduan you yiduan de kuankuo haitan, ling ren zhaomi that one-stretch and one-stretch DE wide beach make people fascinated "The stretches of beaches, which are wide objects, are fascinating."

b. 那一段又一段寬闊的海灘令人著迷。

Na yiduan you yiduan kuankuo de haitan, ling ren zhaomi that one-stretch and one-stretch wide DE beach make people fascinated "The stretches of beaches, which are wider than average beaches, are fascinating."

In (10a), the beaches are fascinating, but not necessarily because they are wide; in (10b), part of the charm of the beaches lies in their width.

D. Absolute versus comparative reading of superlatives

The same contrast can be observed in superlatives, which are formed by attaching $z u i$ "most" to an adjective.

（11）a. 他錄取了, 因為他達到了錄取最低分數。

Ta luqu -le, yinwei ta dadao-le luqu zuidi fenshu

he accept-PERF because he reach-PERF accept lowest score

"He was accepted, because he reached the minimum score for acceptance."

b. ?*他錄取了, 因為他達到了錄取最低的分數。

Ta luqu -le, yinwei ta dadao-le luqu de zuidi fenshu

he accept-PERF because he reach-PERF accept DE lowest score

?"He was accepted, because he reached the lowest score (among ones that are) accepted."

In (11a), the Adj $\mathrm{N}$ has the absolute reading of "minimum score," while in (11b), the Adj de $\mathrm{N}$ has the comparative reading of "lowest score." (11b) is odd because having the lowest score among the accepted applicants is not the reason why someone was accepted.

E. Specific versus nonspecific reading

Another difference concerns whether the $\mathrm{N}$ has a specific or nonspecific reading. The Adj $\mathrm{N}$ phrase has a specific reading, while the Adj de $\mathrm{N}$ phrase could be specific or nonspecific.

(12) a. 聽說他在新開酒吧里, 我去把他叫回來。

Tingshuo ta zai xinkai jiuba li, wo qu ba ta jiao huilai hear-say he at newly-opened bar in I go BA him call return-DIR "I heard that he is at the newly-opened bar; I'll go get him." 
b. *聽說他在新開酒吧里, 可是不知道是哪一家。

Tingshuo ta zai xinkai jiuba li, *keshi bu zhidao shi nayi jia hear-say he at newly-opened bar in but not know is which CL *"I heard that he is at the newly-opened bar, but I don't know which one."

(13) a. 聽說他在新開的酒吧里, 我去把他叫回来。
Tingshuo ta zai xinkai
de jiuba li, wo qu ba ta jiao huilai hear-say he at newly-opened DE bar in I go BA him call return-DIR "I heard that he is at a newly-opened bar; I'll go get him."

b. 聽說他在新開的酒吧里, 可是不知道是哪一家。

Tingshuo ta zai xinkai de jiuba li, *keshi bu zhidao shi nayi jia hear-say he at newly-opened DE bar in but not know is which CL "I heard that he is at a newly-opened bar, but I don't know which one."

In (12), the speaker has a particular bar in mind; (12b) is unacceptable because it is incoherent. In (13), the speaker may or may not have a particular bar in mind, and both (13a) and (13b) are acceptable.

\section{F. Idiomatic versus literal meaning}

Idiomatic meanings are only available in an Adj $\mathrm{N}$ phrase but not in an Adj de $\mathrm{N}$ phrase. For example, when the adjective ying "hard" occurs in an Adj N phrase, it may have a literal meaning or an idiomatic meaning, as illustrated in (14); but when it occurs in an Adj de $\mathrm{N}$ phrase, it only has the literal meaning, as in (15).

（14）a. 請你拿一塊硬紙板來。

Qing ni na yikuai ying zhiban lai please you bring one-CL hard cardboard DIR

"Could you bring a piece of hard cardboard over?"

b. 他有硬脾氣, 很難跟人相處。

Ta you ying piqi, hen nan gen ren xiangchu he has hard temper, very difficult with people get-along "He is inflexible; it is difficult for him to get along with people."

(15) a. 請你拿一塊硬的紙板來。

Qing ni na yikuai ying de zhiban lai please you bring one-CL hard DE cardboard DIR "Could you bring a piece of cardboard over?"

b. *他有硬的脾氣, 很難跟人相處。

Ta you ying de piqi, hen nan gen ren xiangchu he has hard DE temper, very difficult with people get-along "He is inflexible; it is difficult for him to get along with people."

These six cases demonstrate that there are systematic meaning differences between the Adj $\mathrm{N}$ and Adj de $\mathrm{N}$ phrases. These differences fall right into the division in (1); in fact, they are a subset of (1). If we take the two groups of meanings as 
corresponding to two syntactic sources, as Cinque proposes, the picture presented by Chinese is similar to that of English and Italian. In all three languages, adjectives derived by reduced relative clauses show a range of interpretations that can be distinguished from adjectives that participate in direct modification.

Meaning differences between $\mathrm{Adj} \mathrm{N}$ and Adj de $\mathrm{N}$ have been noted in previous studies. According to Zhu (1980 [1956]), Adj N expressions characterize a new subtype of entities or represent phrases that are relatively stable. In contrast, Adj de $\mathrm{N}$ phrases have a temporary quality. Fu (1987) offers a similar characterization: $d e$-less adjectives give a permanent property of the entity denoted by the noun, while with-de adjectives give a temporary property of the entity. Paul $(2005,2010)$ characterizes the differences as defining versus accessory. The analysis proposed here is compatible with these previous studies. In fact, each of the six cases presented above can be considered as an instantiation of the difference between characterizing/permanent/defining versus temporary/accessory properties. But by framing the differences in terms of Cinque's classification, our analysis goes one step further; it demonstrates the various dimensions of the contrast between permanent and temporary, and it also highlights the cross-linguistic nature of the syntax-semantic association between the two types of modification. In particular, it allows for meaningful comparisons between Chinese and English, Italian, or other languages that display the pattern in (1). An example of such comparisons is provided in Section 3.3.

\subsection{One source for nonpredicative adjectives}

After demonstrating that predicative adjectives come from two sources, depending on whether the adjectives are with-de or de-less, it is important to return to nonpredicative adjectives and consider whether they also display meaning differences between Adj $\mathrm{N}$ and Adj de N. As discussed in Section 2, these adjectives only have one syntactic source, that of direct modification, and therefore, they are expected to have the same interpretation with or without de. Is this prediction supported?

Lü and Rao (1981) note that nonpredicative adjectives, with or without de, denote properties/characteristics of things ("shiwu de xingzhi") (p. 81), and they refer to these adjectives as "characterizing words" ("shuxing ci"). Indeed, the adjectives in (16) all have a characterizing function - they create a subtype of entities:

(16) a. xishi (de) zaocan

"Western-style breakfast"

b. daxing (de) yinyuhui "large-scale concert"

c. liangxing (de) bingdu "benign virus"

d. shangdeng (de) putaojiu "top-level wine" 
e. gaoji (de) xiangshou

"high-level entertainment"

f. dahao (de) chenshan "large-size shirt"

g. duanqi (de) fangwen "short visit"

Consider (17) and (18), which includes (16a) and (16f), respectively:
a. Nafen xishi
zaocan ta chi de manyi ji
le that-CL Wstern-style breakfast he eat DEG satisfied extreme PRT "He was completely satisfied with the Western-style breakfast."
b.Nafen xishi de zaocan ta chi de manyi ji le that-CL Western-style DE breakfast he eat DEG satisfied extreme PRT "He was completely satisfied with the Western-style breakfast."

(18) a. Ta suiran gezi xiao, keshi jingchang chuan dahao chenshan he although size small but often wear large-size shirt "Even though he is small, he often wears large-size shirts."

b. Ta suiran gezi xiao, keshijingchang chuan dahao de chenshan he although size small but often wear large-size DE shirt "Even though he is small, he often wears large-size shirts."

In (17), xishi zaocan "Western-style breakfast" and xishi de zaocan "Westernstyle breakfast" have the same meaning, characterizing a type of breakfast; similarly, in (18), dahao chenshan "large-size shirt" and dahao de chenshan "large-size shirt" have the same meaning, characterizing a type of shirts. The occurrence of de in (17b) and (18b) does not alter the function the adjective. This is supported by placing the adjectives in an identification context, which brings out the characterizing function of adjectives (Fu 1987). As (19) and (20) shows, in this context, nonpredicative adjectives can occur with or without de:
a. Zhe shi xishi zaocan
this is Western-style breakfast
"This is Western-style breakfast."
b.Zhe shi xishi de zaocan
this is Western-style DE breakfast
"This is Western-style breakfast."

(20) a.Zhe shi dahao chenshan

this is large-size shirt

"This is a large-size shirt."

b.Zhe shi dahao de chenshan

this is large-size DE shirt

"This is a large-size shirt." 
The same applies to the other adjectives in (16). In contrast, predicative adjectives in the same context disprefer the occurrence of de, because Adj de $\mathrm{N}$ signals a temporary property of the entity, in conflict with the requirement of an identification context:

(21) a. Zhe shi lü huaping

this is green vase

"This is a green vase."

b. ?*Zhe shi lü de huaping

this is green DE vase

"This is a green vase."

(22) a. Zhe shi xinxian mianbao

this is fresh bread

"This is fresh bread."

b. ?*Zhe shi xinxian de mianbao

this is fresh DE bread

"This is fresh bread."

In short, the prediction concerning the meaning of nonpredicative adjectives is borne out: these adjectives, with or without $d e$, have only one meaning, that of characterizing an entity, and it is associated with direct modification.

(23) summarizes what we have so far in terms of syntactic sources:

(23) Adjectives in Chinese

Adjectives

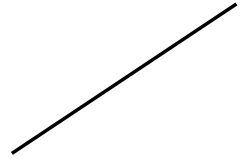

Nonpredicative

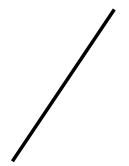

Without de

$\mid$

Direct mod

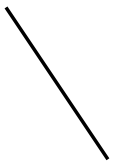

With de

$$
\mid
$$

Direct mod

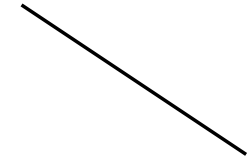

Predicative

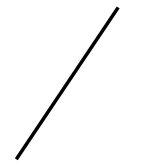

Without de

With de

$$
\mid
$$

Direct mod

Reduced RC 


\subsection{Comparisons between Chinese and English}

Cinque (2014), following Partee (2007, 2009, 2010), reaches the conclusion that the major division of adjectives is between predicative and nonpredicative adjectives, which for English adnominal adjectives, corresponds to the distinction between reduced relative clauses and direct modification. (24) shows how adnominal adjectives are divided in English:

(24) Adnominal adjectives in English

Adnominal adjectives

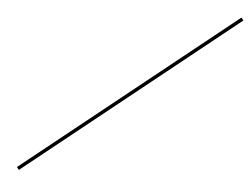

Prenominal

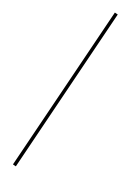

Nonpredicative

$$
\mid
$$

Direct mod

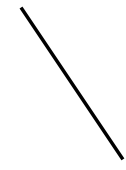

Predicative

$$
\mid
$$

Reduced RC

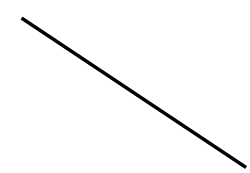

Postnominal

$$
\mid
$$

Predicative

$$
\mid
$$

Reduced RC

How does the English situation in (24) relate to the Chinese situation in (23)? If, as suggested in Section 3.1, Chinese predicative adjectives display a divide as characterized by (1), we would expect to see similarities between Chinese and English. (23) and (24) do have something in common - in both languages, if an adjective has reduced relative clause as its source, it is predicative. But we also see differences. In Chinese, predicative adjectives are not all derived from reduced relative clauses; a subgroup of predicative adjectives (ones without de) participate in direct modification. In contrast, in English, predicative adjectives are all derived from reduced relative clauses.

On closer examination, however, this difference (whether some predicative adjectives are associated with direct modification) disappears. This is because the term "predicative" is used differently by Cinque and Chinese grammarians. For Cinque, whether an adjective is predicative depends on how it is used: a predicative 
adjective is one that is used predicatively, having the same semantic properties as reduced relative clause. The same lexical item, for example, beautiful, may have a predicative use and a nonpredicative use. For Chinese grammarians, for example, Lü and Rao (1981), whether an adjective is predicative depends on whether it can be used predicatively. If an adjective can be used predicatively, it is predicative, regardless of how it is actually used. For example, a beautiful dancer is ambiguous between "a dancer who is physically beautiful" and "a dancer who dances beautifully." In the latter reading, beautiful has a nonpredicative use. For Cinque, this use is a case of nonpredicative adjective and goes under the nonpredicative branch in (24), but for Lü and Rao, the adjective beautiful is predicative in either use. If we follow Cinque, interpreting "predicative" as "being used predicatively," the adjective meili "beautiful" in meili wuzhe "beautiful dancer" will be grouped into the nonpredicative branch. We can, therefore, revise (23) as (25):

(25) Adjectives in Chinese (revised)

Adjectives

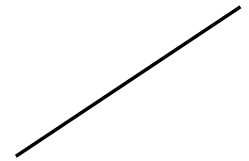

Nonpredicative

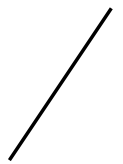

Without de

$$
\mid
$$

Direct mod

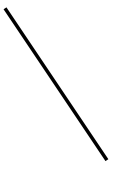

With de

$$
\mid
$$

Direct mod

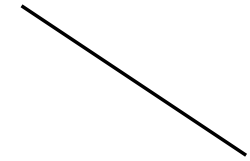

Predicative

$$
\mid
$$

With de

$$
\mid
$$

Reduced RC

(25) is now similar to (24). In both cases, predicative adjectives are derived from reduced relative clauses, and nonpredicative adjectives participate in direct modification. By doing so, we see that despite superficial differences, adjectives in Chinese are parallel to adjectives in English in an important way: the divide between syntactic sources corresponds to the distinction between predicative versus nonpredicative adjectives. This correlation is exactly what Cinque outlines for Italian and English. 
(25) captures the parallelism between Chinese and English (nonpredicative maps to direct modification and predicative maps to reduced RC), but in terms of procedure, that is, steps to take in deciding the syntactic source of an adjective, (26), which gives the same information as (25), is easier to follow:

(26) Adjectives in Chinese (alternative presentation of (25))

\section{Adjectives}

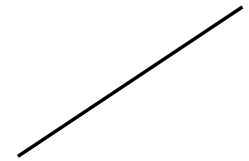

Without de

$$
\mid
$$

Nonpredicative

$$
\mid
$$

Direct mod

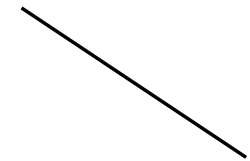

With de

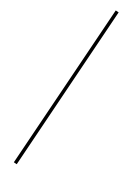

Nonpredicative

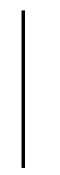

Direct mod
Predicative

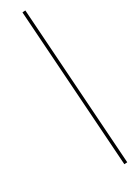

$$
\mid
$$

Reduced RC

(26) says that if an adjective occurs in $\mathrm{Adj} \mathrm{N}$, it is a case of direct modification and it is nonpredicative. If an adjective occurs in $\operatorname{Adj} d e \mathrm{~N}$, it is derived from reduced RC if it is used predicatively; otherwise, it is nonpredicative and participates in direct modification. Thus the syntactic source of adjectives in Chinese is determined by two factors: form (Adj N vs. Adj de N) and use (predicative vs. non-predicative). These are precisely the two distinctions mentioned at the beginning of the study. We now see that both of them play a role in determining the syntactic source of an adjective.

\section{Conclusion}

I have argued that Cinque's $(2010,2014)$ analysis of the association between syntactic sources and interpretive properties also applies to Chinese. Adjectives in Chinese that are derived from relative clauses are semantically different from those that directly modify nouns in ways described by Cinque. In this aspect, Chinese is similar to English and Italian. I have also shown that once "predicative" 
is interpreted in the same way between the two languages, Chinese is parallel to English and displays the correspondence that predicative adjectives are derived from reduced $\mathrm{RC}$, while nonpredicative adjectives participate in direct modification. The Chinese data thus lends further support for Cinque's conclusion and suggests that the correspondence may hold cross-linguistically. On the other hand, the comparative data between English and Chinese has implications for the study of Chinese adjectives. In particular, it suggests that the term "nonpredicative" ("fei wei xingrongci") should be applied to a broader group than what has been assumed so far; it should include not only the adjectives in Lü and Rao (1981) but also all other adjectives that enter Adj N. This will allow us to see that despite superficial differences, Chinese adjectives have much in common with English adjectives syntactically and semantically.

\section{Acknowledgments}

This note was inspired by Cinque's (2014) article. I am indebted to the reviewers for their comments and suggestions. One reviewer's detailed comments are especially appreciated.

\section{References}

Aoun, Joseph \& Yen-hui Audrey Li. 2003. Essays on the representational and derivational nature of grammar. The diversity of wh-constructions. Cambridge, MA: MIT Press.

Cinque, Guglielmo. 2010. The syntax of adjectives. A comparative study. Cambridge, MA: MIT Press.

Cinque, Guglielmo. 2014. The semantic classification of adjectives. A view from syntax. Studies in Chinese Linguistics 35(1). 1-30.

Duanmu, San. 1998. Wordhood in Chinese. In Jerome Lee Packward (ed.), New approaches to Chinese word formation: Morphology, phonology and the lexicon in modern and ancient Chinese, 135-196. Berlin and New York: Mouton de Gruyter.

Fan, Jiyan. 1958. Xing ming zuhe jian "de" zi de jufa zuoyong [Syntactic functions of de in adjective-de-noun structure]. Zhongguo Yuwen 5. 213-217.

$\mathrm{Fu}$, Jingqi. 1987. La structure du syntagme nominal en chinois. Paris: University of Paris dissertation.

Lü, Shuxiang. 1979. Hanyu yufa fenxi wenti [Problems in the analysis of Chinese grammar]. Beijing: Commercial Press.

Lü, Shuxiang \& Changrong Rao. 1981. Shi lun fei wei xingrongci [On non-predicative adjectives]. Zhongguo Yuwen 2. 81-85.

Partee, Barbara H. 2007. Compositionality and coercion in semantics: The dynamics of adjective meaning. In Gerlof Bouma, Irene Krämer \& Joost Zwarts (eds.), Cognitive foundations of interpretation, 145-161. Amsterdam: Royal Netherlands Academy of Arts and Sciences.

Partee, Barbara H. 2009. Formal semantics, lexical semantics, and compositionality: The puzzle of privative adjectives. Philologia 7. 7-19. 
Partee, Barbara H. 2010. Privative adjectives: Subsective plus coercion. In Rainer Bauerle, Uwe Reyle \& Thomas Ede Zimmermann (eds.), Presuppositions and discourse: Essays offered to Hans Kamp, 273-285. Bingley: Emerald Group Publishing Limited.

Paul, Waltraud. 2005. Adjective modification in Mandarin Chinese and related issues. Linguistics 43. 757-793.

Paul, Waltraud. 2010. Adjectives in Mandarin Chinese: The rehabilitation of a much ostracized category. In Patricia Cabredo Hofherr \& Ora Matushansky (eds.), Adjectives: Formal analyses in syntax and semantics, 115-152. Amsterdam: John Benjamins.

Sproat, Richard \& Chilin Shih. 1988. Prenominal adjectival ordering in English and Chinese. In James L. Blevins \& Juli Carter (eds.), Proceedings of NELS 18(2), 465-489. Amherst, MA: GLSA.

Sproat, Richard \& Chilin Shih. 1991. The cross-linguistic distribution of adjective ordering restrictions. In Carol Georgopoulos \& Roberta Ishihara (eds.), Interdisciplinary approaches to languages: Essays in honor of S-Y. Kuroda, 565592. Dordrecht: Kluwer.

Zhu, Dexi. 1980 [1956]. Xiandai Hanyu xingrongci yanjiu [A study of adjectives in Modern Chinese]. In Xiandai Hanyu yufa yanjiu [Studies on modern Chinese grammar], 3-41. Beijing: Commercial Press.

Zhu, Dexi. 1982. Yufa jiangyi [Lectures on grammar]. Beijing: Commercial Press.

Address: Department of East Asian Studies, University of Arizona, Tucson, AZ 85721, USA

Email: fliu@email.arizona.edu

Received: December 15, 2014

Accepted: July 8, 2015 


\title{
漢語形容詞的句法來源
}

\author{
劉鳳樨 \\ 亞利桑那大學
}

\section{提要}

Cinque $(2010,2014)$ 認為作定語的形容詞有兩個句法來源, 並為英語和義大利語提 供證據指出不同來源之形容詞帶有不同的語義, 句法來源的不同最終歸究於形容詞 是否用作謂語。本文探討漢語形容詞的句法來源, 證據顯示漢語形容詞同樣有兩個 來源：直接修飾以及關係小句, 前者與後者顯現不同語義。形容詞是否用作謂語在 漢語也發揮同樣作用, 對形容詞的句法來源有決定性因素。但漢語和英語, 義大利 語的相似之處只有在以下情況才能呈現出來：漢語 “謂語性形容詞” 與 “非謂語性 形容詞” 的區分必須重新規劃, 所有不加 “的” 的形名詞組中的形容詞皆應納入非 謂語性形容詞中。

\section{關鍵詞}

形容詞, 非謂語性, 直接修飾, 關係小句 